\title{
Outcomes of hospitalizations with atrial fibrillation-flutter on a weekday versus weekend: an analysis from a 2014 nationwide inpatient sample
}

\author{
Dinesh C Voruganti ${ }^{\text {Corresp.. }}{ }^{1}$, Ghanshyam Palamaner Subash Shantha ${ }^{2}$, Abhishek Deshmukh ${ }^{3}$, Michael C Giudici \\ 1 Division of Internal Medicine, Roy and Lucille J. Carver College of Medicine, University of lowa Hospitals and Clinics, lowa City, lowa, United States \\ 2 Division of Cardiovascular Medicine, University of Michigan - Ann Arbor, Ann Arbor, Michigan, United States \\ 3 Division of Cardiovascular Medicine, Mayo Clinic, Rochester, Minnesota, United States \\ 4 Division of Cardiovascular Medicine, Roy and Lucille J. Carver College of Medicine, University of lowa Hospitals and Clinics, lowa City, lowa, United States \\ Corresponding Author: Dinesh C Voruganti \\ Email address: dinesh-voruganti@uiowa.edu
}

Background:Patients with atrial fibrillation-flutter (AF) admitted on the weekends were initially reported to have poor outcomes. The primary purpose of this study is to re-evaluate the outcomes for weekend versus weekday AF hospitalization using the 2014 Nationwide Inpatient Sample (NIS).

Methods:Included hospitalizations were aged above 18 years. The hospitalizations with AF were identified using the international classification of diseases 9 (ICD-9) codes (427.31, 427.32). In-hospital mortality, length of stay (LOS), other co-morbidities, cardioversion procedures, and time to cardioversion were recorded. All analysis was performed using SAS 9.4 statistical software (Cary, North Carolina).

Results: A total of 453,505 hospitalizations with atrial fibrillation and flutter as primary discharge diagnosis were identified. Among the total hospitalizations with a primary diagnosis of AF, 20.3\% were admitted on the weekend. Among the weekend hospitalizations, $0.19 \%$ died in hospital compared to $0.74 \%$ among those admitted during the week. After adjusting for patient characteristics, hospital characteristics and disease severity, the adjusted odds for in-hospital mortality were not significantly different for weekend vs. weekday hospitalizations ( $\mathrm{OR}=0.91,95 \% \mathrm{Cl}=0.77-1.11 ; \mathrm{p}=0.33)$. The weekend admissions were associated with significantly lower odds of cardioversion procedures (OR $=0.72,95 \%$ $\mathrm{Cl}=0.69-0.76, \mathrm{P}<0.0001$ ), lower cost of hospitalization (USD 8265.8 on weekends vs. USD 8966.5 on the weekdays, $\mathrm{P}<0.001$ ), slightly lower rate of anticoagulation (17.09\% on the weekends vs. $18.73 \%$ on the weekdays. $\mathrm{P}<0.0001$ ), and slightly increased time to cardioversion ( 1.94 days on the weekend vs. 1.73 days on weekdays, $\mathrm{P}<0.0005)$. The mean length of hospital stay (LOS) was statistically not different in both groups: ( 3.49 days \pm 3.70 (SD)in the weekend group vs. 3.47 days \pm 3.50 (SD)in the weekday group, $P=0.42$ )

Discussion:The weekend AF hospitalizations did not have a clinically significant difference in mortality and LOS compared to those admitted on a weekday. However, the use of cardioversion procedures and cost of hospitalization was significantly lower on the weekends. 
1 Outcomes of hospitalizations with atrial fibrillation-flutter on a weekday versus weekend:

2

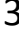

4 Dinesh C Voruganti MBBS ${ }^{\mathrm{a}}$, Ghanshyam Palamaner Subash Shantha MBBS ${ }^{\mathrm{b}}$, Abhishek

5 Deshmukh $\mathrm{MD}^{\mathrm{c}}$, Michael C Giudici $\mathrm{MD}^{\mathrm{d}}$.

6

7 a: Division of Internal Medicine, Roy and Lucille J. Carver College of Medicine, University of

8 Iowa Hospitals and Clinics, Iowa City, Iowa, USA

9 b: Division of Cardiovascular Medicine, University of Michigan, Ann Arbor, Michigan, USA

10 c: Division of Cardiovascular Medicine, Mayo Clinic, Rochester, Minnesota, USA

11 d: Division of Cardiovascular Medicine, Roy and Lucille J. Carver College of Medicine,

12 University of Iowa Hospitals and Clinics, Iowa City, Iowa, USA

13 Total word count: 2747

14 Address for correspondence: Dinesh Chandra Voruganti MBBS,

Division of Internal Medicine, University of Iowa Hospitals and Clinics,

16200 Hawkins Dr., Internal Medicine, Iowa City, IA 52242.

17 Telephone number: 319-353-7858.

18 Fax: 319-353-8073.

19

Email: dinesh-voruganti@uiowa.edu

21

22 
$\underline{\text { Abstract }}$

25

26

27

28

29

30

31

32

33

34

35

36

37

38

39

40

41

42

43

44

45

46

47

48

49

50

51

52

53

54

55

Background: Patients with atrial fibrillation-flutter (AF) admitted on the weekends were initially reported to have poor outcomes. The primary purpose of this study is to re-evaluate the outcomes for weekend versus weekday AF hospitalization using the 2014 Nationwide Inpatient Sample (NIS).

Methods: Included hospitalizations were aged above 18 years. The hospitalizations with AF were identified using the international classification of diseases 9 (ICD-9) codes (427.31, 427.32). In-hospital mortality, length of stay (LOS), other co-morbidities, cardioversion procedures, and time to cardioversion were recorded. All analysis was performed using SAS 9.4 statistical software (Cary, North Carolina).

Results: A total of 453,505 hospitalizations with atrial fibrillation and flutter as primary discharge diagnosis were identified. Among the total hospitalizations with a primary diagnosis of AF, $20.3 \%$ were admitted on the weekend. Among the weekend hospitalizations, $0.19 \%$ died in hospital compared to $0.74 \%$ among those admitted during the week. After adjusting for patient characteristics, hospital characteristics and disease severity, the adjusted odds for in-hospital mortality were not significantly different for weekend vs. weekday hospitalizations ( $\mathrm{OR}=0.91$, $95 \% \mathrm{CI}=0.77-1.11 ; \mathrm{p}=0.33)$. The weekend admissions were associated with significantly lower odds of cardioversion procedures $(\mathrm{OR}=0.72,95 \% \mathrm{CI}=0.69-0.76, \mathrm{P}<0.0001)$, lower cost of hospitalization (USD 8265.8 on weekends vs. USD 8966.5 on the weekdays, $\mathrm{P}<0.001$ ), slightly lower rate of anticoagulation $(17.09 \%$ on the weekends vs. $18.73 \%$ on the weekdays. $\mathrm{P}<$ 0.0001 ), and slightly increased time to cardioversion (1.94 days on the weekend vs. 1.73 days on weekdays, $\mathrm{P}<0.0005$ ). The mean length of hospital stay (LOS) was statistically not different in both groups: (3.49 days \pm 3.70 (SD)in the weekend group vs. 3.47 days \pm 3.50 (SD)in the weekday group, $\mathrm{P}=0.42$ )

Discussion: The weekend AF hospitalizations did not have a clinically significant difference in mortality and LOS compared to those admitted on a weekday. However, the use of cardioversion procedures and cost of hospitalization was significantly lower on the weekends. 


\section{Introduction}

57 Atrial fibrillation is the most common persistent cardiac arrhythmia in clinical practice which

58 had an estimated worldwide prevalence of 33.5 million in 2010. (Markides \& Schilling 2003)

59 Patients with atrial fibrillation-flutter (AF) hospitalized on weekends were previously reported to

60 have higher mortality and increased the length of hospital stay. (Deshmukh et al. 2012; Shawn

61 Lee ) The factors thought to be contributing to the poor outcomes are: limited availability of the

62 staff and access to procedures such as cardioversion. Similar studies on acute myocardial

63 infarction have demonstrated higher inpatient mortality for weekend hospitalizations. (de

64 Cordova et al. 2017) A similar analysis on AF weekend hospitalizations reported improved

65 mortality, (Weeda et al. 2016) but the improvement in these outcomes were consistently not

66 replicated by studies performed on a large database on inpatient hospitalizations. We sought to

67 investigate the outcomes in the year 2014 through publically available nationwide inpatient

68 sample database (NIS) to assess the outcomes (in-hospital mortality, rates of cardioversion and

69 time to cardioversion) and to determine whether such differences resulted from the disparities in

70 the utilization and timing of cardioversion.

71

72

\section{Methods}

73

74 The NIS is a part of the Healthcare Cost and Utilization Project (HCUP) which is

75 sponsored by the Agency for Healthcare Research and Quality (AHRQ). (HCUP 2012) Each

76 year of the NIS records over 7 million inpatient hospitalizations. The NIS is one of the largest

77 all-payer databases of hospital inpatient stays available in the United States of America (USA).

78 The $2014\left(1^{\text {st }}\right.$ January to $31^{\text {st }}$ December $)$ NIS sampling frame is comprised of 44 States and the 
79 District of Columbia, covering more than 96 percent of the U.S.A population and including more 80 than 94 percent of discharges from the USA community hospitals.

81

Our main interest group was the hospitalizations who had a primary diagnosis $(\mathrm{dx} 1)$ of

83

84

85

86

87

90

91

92

93

94

95

The study protocol was reviewed by the University of Iowa, Iowa City, Institutional

Review Board (IRB) (review: 201806023), and the study was exempt from human subject research as it includes only de-identified, publically available data. All analyses were performed using SAS, version 9.4 (SAS Institute, Cary, North Carolina). Survey procedures available within the SAS were applied in the analysis to account for design features of the complex sample survey. Descriptive statistics were generated for the individual and hospital characteristics for both weekend and weekday admissions. Univariate tests were applied to compare the equality of the mean or proportions for the motioned outcomes between the weekday and weekend admissions, which consisted of the Rao-Scott chi-square test for categorical outcomes and t-tests (along with standard deviation (SD)) for continuous outcomes. The cost of hospitalization was calculated from cost to charge ratio files and the total charges provided by the AHRQ. 
102 (https://www.hcup-us.ahrq.gov/db/state/costtocharge.jsp) The number of chronic conditions was

103 obtained from 'NCHRONIC' variable listed in the NIS database. The data element

104 'NCHRONIC' contains the count of unique chronic diagnoses reported on the discharge. The

105 long-term (current) use of anticoagulants was determined using the ICD -9 CM code 'V58.61'.

106 The national estimates for hospitalization were calculated by applying the weights provided by

107 the HCUP-AHRQ in the NIS file. Finally, multivariate logistic regression models were applied 108 to test the adjusted associations between the outcomes of weekend versus weekday admissions.

109 The level of significance $(\alpha)$ was chosen as $5 \%$.

110

111

112

113

114

115

116

117

118

119

120

121 (6.25 on weekends vs. 5.34 on the weekdays, $\mathrm{P}<0.0001$ ). Hospitalizations with Medicare

122 constituted the majority of overall hospitalizations (67.13\%) for AF. AF hospitalizations were

123 relatively higher in the Urban teaching hospitals (59.61\%), and the weekday hospitalizations

124 were higher in the urban teaching hospitals vs. the weekend (60.12 on the weekday vs. $57.63 \%$ 
125 on the weekends, $\mathrm{P}<0.0001)$. The same pattern was observed in the large hospitals which

126 constituted about $50.64 \%$ of total AF hospitalizations, and a slightly higher rate of AF

127 hospitalizations in the large hospitals was on the weekdays (51.08\% on the weekday vs. $48.93 \%$

128 on the weekends, $\mathrm{P}<0.0001)$. Table 1 summarizes the demographics and baseline characteristics

129 for the weekday and weekend hospitalizations along with the P values (T-test for continuous

130 variables and Chi-square test for the categorical variables).

131 Comparing the in-hospital mortality (primary outcome) in two groups, we have identified

132 that the mortality for weekend hospitalizations did not significantly vary from the weekday

133 hospitalizations $(0.19 \%$ on the weekends vs. $0.74 \%$ on the weekdays, $\mathrm{P}=0.90)$.

Secondary outcomes were the number of inpatient cardioversion procedures, interval to

136 the procedure (time to cardioversion), length of stay, anticoagulation and the cost of

137 hospitalization. These characteristics are listed in Table 2. We noted that the weekend AF

138 hospitalizations underwent fewer cardioversion procedures than those hospitalized on a weekday

$139(2.90 \%$ vs. $14.83 \%, \mathrm{p}<0.0001)$. The average time to cardioversion was not very different among

140 both groups, though statistically significant (1.94 days on the weekend vs. 1.73 days on a

141 weekday, $\mathrm{P}=0.0005)$. The weekend $\mathrm{AF}$ admission was associated with a lower cost of

142 hospitalization (USD 8265.8 on weekends vs. USD 8966.5 on the weekdays, $\mathrm{P}<0.001$ ). The

143 weekend hospitalizations had a slightly lower rate of anticoagulation $(17.09 \%$ on the weekends

144 vs. $18.73 \%$ on the weekdays. $\mathrm{P}<0.0001)$.

145

The univariate (table 3) and the multivariate logistic regression analysis for in-hospital

147 mortality were performed, after adjusting for significant covariates such as age, sex, 
148 hypertension, obesity, diabetes mellitus, congestive heart failure, stroke, anticoagulation, length

149 of stay(LOS), primary expected payer, race, hospital location and the teaching status. We

150 observed that the weekend hospitalizations did not have significant difference for in-hospital

151 mortality $\mathrm{OR}=0.917(95 \% \mathrm{CI} 0.77-1.092 ; \mathrm{P}=0.3299)($ described in Table 4, Figure 1$)$. Also, we

152 observed that the hospitalizations with a diagnosis of stroke and presence of 5 or more chronic

153 conditions had the most significant association with in-hospital mortality $\mathrm{OR}=1.609(95 \% \mathrm{CI}$

$1541.214-2.132, \mathrm{P}=0.0009)$ and $\mathrm{OR}=1.423(95 \% \mathrm{CI} 1.074-1.886, \mathrm{P}=0.014)$ respectively.

155

156

157

\section{Discussion}

158

159

The main inferences of our analysis on the NIS 2014 data are 1) AF weekend

160

hospitalizations showed no clinically significant differences in mortality, length of stay, time to

161

cardioversion, 2). We also found that weekend hospitalizations were less likely to undergo

162

cardioversion, and 3). they had overall lower mean cost of hospitalization.

163

164

Prior study on AF weekend hospitalization by Deskhmukh et al.(Deshmukh et al. 2012)

165

reported the adjusted in-hospital mortality to be higher for weekend admissions (OR 1.23, CI

166

1.03-1.51), longer weekend length of hospitalization and lower rates of utilization of

167 cardioversion ( $7.92 \%$ weekend vs. $16.2 \%$ weekday). Similarly, another study by Weeda et al.

168 (Weeda et al. 2016) has reported that there were no differences in the adjusted in-hospital

169 mortality rate (OR 1.02; $95 \%$ CI $0.94-1.11)$ and the length of hospitalization. However, they 
170 were found to have longer time-to-procedure and lesser treatment costs with weekend

171 admissions.

172

173 In comparison to the prior studies, our results match Deshmukh et al. where the

174 utilization of cardioversion and cost of hospitalization was lower in weekend AF

175 hospitalizations. On the other hand, our analysis also matches Weeda et al. in demonstrating a

176 lack of significant difference in mortality and the length of hospitalization stay among both

177 groups comparing weekend and weekday admissions. The outcomes on the weekend are

178 informally referred to as the 'weekend effect.' It is a phenomenon which is often highlighted to

179 associate poor outcomes in weekend hospitalizations. It has been proposed that it might be a

180 result of lack of healthcare management organizations to improve practices of care, which

181 includes ensuring round the clock accessibility to life-saving procedures. (Mathew et al. 2018)

182 Also, published meta-analysis has associated poor outcomes in patients admitted with

183 myocardial infarction and other medical conditions. (Sorita et al. 2014) In patients with AF, the

184 higher mortality, length of stay and lower utilization of cardioversion procedures were thought to

185 be secondary to limited availability of services on the weekends. It was proposed that the subtle

186 primary signs of acute problems go unnoticed until later on the weekends. Studies focused on the

187 weekend effects, in general, have emphasized for a better-organized model of care which could

188 help in bridging the gap of the weekend effect.

189 We notice an improvement of outcomes in hospitalizations with AF. The difference of

190 in-hospital mortality, length of hospitalization, and time to cardioversion has been gradually

191 decreasing since Deshmukh et al.'s publication. These changes might occur due to the

192 implementation of robust patient care across the hospitals in the United States to provide 24/7 
193 accessibility to procedures such as cardioversion and prompt recognition of subtle clinical

194 parameters such as atrial fibrillation with rapid ventricular response with improvised

195 computerized telemetry, resulting in early transfer to the intensive care unit for cardioversion on

196 the weekends. (Albright et al. 2009; Conway et al. 2018) However, utilization rates of

197 cardioversion continue to be low among the weekend AF hospitalizations. One of the reasons

198 might be due to limited staff availability and sometimes, delay in identifying subtle signs of

199 acute problems, such as hypotension, may go unnoticed until later.

200 On the other hand, the lack of mortality difference on the weekends with a lower cost of

201 hospitalization and lower rates of utilization of cardioversion procedures also raise a concern

202 about the higher costs of hospitalization on the weekdays. We notice a higher rate of

203 cardioversion procedures on the weekdays which might also sometimes imply overutilization of

204 the procedures, resulting in a higher cost of hospitalization. While opportunities to improve care

205 on the weekends are constantly being explored, a cost-effective management strategy may also

206 be pursued to reduce the costs of hospitalizations on the weekdays. In our analysis, we noted

207 low anticoagulation rates in both the weekend and the weekday groups, which is in

208 concordance with the report from the Get with the Guidelines registry that showed

209 similarly low rates (15\% to $17 \%$ ) of anticoagulation in their AF patients.(Piccini et al.

210 2016) The low anticoagulation rates are probably because of high bleeding risk, higher

211 prevalence of contraindications to anticoagulation in AF patients, or due to the coding

212 inconsistencies.

213 Future directions should be focused on improving the utilization rates of cardioversion

214 procedures and assessing the reasons for the disparity between the hospitalization costs

215 associated with weekend hospitalizations. Our study findings provide valuable data 
216 demonstrating the improved mortality outcomes and length of hospitalization. Understanding the

217 reasons behind the decreased cost of admission on weekends and reduced utilization of

218 cardioversion procedures might help to bridge the gap difference.

219

220

221

222

223

224

225

226

227

228

229

230

231

232

233

234

235

236

237

238

239

240

241

242

Though our study had essential strengths of including a large sample, our study is subject

to some limitations. First, the NIS relies on claims data which can incur inaccurate billing and underestimation of covariates of interest, thus leading to coding bias. (Yoshihara \& Yoneoka 2014) Missing values in our data prevented us from including specific variables in the multivariate analysis. Furthermore, we did not evaluate the causes that could have accounted for this difference that are not patient related but related to the hospital (e.g., staffing differences on weekends).

Conclusion

In the nationwide US practice, the weekend AF hospitalizations appear to have lower rates of cardioversion utilization. Further studies are required to identify the differences and explore the opportunities to improve AF weekend care.

https://www.hcup-us.ahrq.gov/db/state/costtocharge.jsp. HCUP COST-TO-CHARGE RATIO FILES AND COST ESTIMATES.

Albright KC, Raman R, Ernstrom K, Hallevi H, Martin-Schild S, Meyer BC, Meyer DM, Morales MM, Grotta JC, Lyden PD, and Savitz SI. 2009. Can comprehensive stroke centers erase the 'weekend effect'? Cerebrovasc Dis 27:107-113. 10.1159/000177916

Ananthakrishnan AN, McGinley EL, and Saeian K. 2009. Outcomes of weekend admissions for upper gastrointestinal hemorrhage: a nationwide analysis. Clin Gastroenterol Hepatol 7:296-302e291. 10.1016/j.cgh.2008.08.013 
243

244

245

246

247

248

249

250

251

252

253

254

255

256

257

258

259

260

261

262

263

264

265

266

267

268

269

270

271

272

273

274

275

276

277

278

279

280

281
Conway R, Cournane S, Byrne D, O'Riordan D, and Silke B. 2018. Improved mortality outcomes over time for weekend emergency medical admissions. Ir J Med Sci 187:5-11. 10.1007/s11845-017-1627-7

de Cordova PB, Johansen ML, Martinez ME, and Cimiotti JP. 2017. Emergency Department Weekend Presentation and Mortality in Patients With Acute Myocardial Infarction. Nursing Research 66:20-27. 10.1097/nnr.0000000000000196

Deshmukh A, Pant S, Kumar G, Bursac Z, Paydak H, and Mehta JL. 2012. Comparison of outcomes of weekend versus weekday admissions for atrial fibrillation. Am J Cardiol 110:208-211. 10.1016/j.amjcard.2012.03.011

HCUP. 2012. HCUP National Inpatient Sample (NIS). Healthcare Cost and Utilization Project (HCUP). 2012. Agency for Healthcare Research and Quality, Rockville, MD.

Markides V, and Schilling RJ. 2003. Atrial fibrillation: classification, pathophysiology, mechanisms and drug treatment. Heart 89:939-943.

Mathew A, Fyyaz SA, Carter PR, and Potluri R. 2018. The enigma of the weekend effect. J Thorac Dis 10:102-105. 10.21037/jtd.2017.12.115

Piccini JP, Simon DN, Steinberg BA, Thomas L, Allen LA, Fonarow GC, Gersh B, Hylek E, Kowey PR, Reiffel JA, Naccarelli GV, Chan PS, Spertus JA, and Peterson ED. 2016. Differences in Clinical and Functional Outcomes of Atrial Fibrillation in Women and Men: Two-Year Results From the ORBIT-AF Registry. JAMA Cardiol 1:282-291. 10.1001/jamacardio.2016.0529

Shawn Lee AL, Farid Gholitabar, Carlos A Gongora, Abel Casso Dominguez, Paul T Kroner, Carolina Hurtado, Daniel Castaneda, and Davendra Mehta. Comparison of Weekday vs. Weekend Admission on Inpatient Mortality and Total Hospital Charge on Atrial Flutter and Fibrillation: A Nationwide Analysis.

Sorita A, Ahmed A, Starr SR, Thompson KM, Reed DA, Prokop L, Shah ND, Murad MH, and Ting HH. 2014. Off-hour presentation and outcomes in patients with acute myocardial infarction: systematic review and meta-analysis. BMJ 348:f7393. 10.1136/bmj.f7393

Weeda ER, Hodgdon N, Do T, Unachukwu K, Cui A, Lundbye JB, and Coleman Cl. 2016. Association between weekend admission for atrial fibrillation or flutter and in-hospital mortality, procedure utilization, length-of-stay and treatment costs. International Journal of Cardiology 202:427-429. 10.1016/j.ijcard.2015.09.053

Yoshihara H, and Yoneoka D. 2014. Understanding the statistics and limitations of large database analyses. Spine (Phila Pa 1976) 39:1311-1312.

10.1097/BRS.0000000000000352 


\section{Figure 1}

Multivariate logistic regression analysis with adjusted odds ratio's for in-hospital mortality.

Figure 1: The adjusted odds ratio's, 95\% confidence intervals and their P-values represent the odds of in-hospital mortality after adjusting for the covariates listed in the table. The blue dots indicate the adjusted odds ratio for the listed variable, and the red lines indicate 95\% confidence intervals. $O R$ to the right of midline (where $O R=1$ ) indicate higher odds of inhospital mortality while OR to the left of the midline indicate lower odds of in-hospital mortality. 


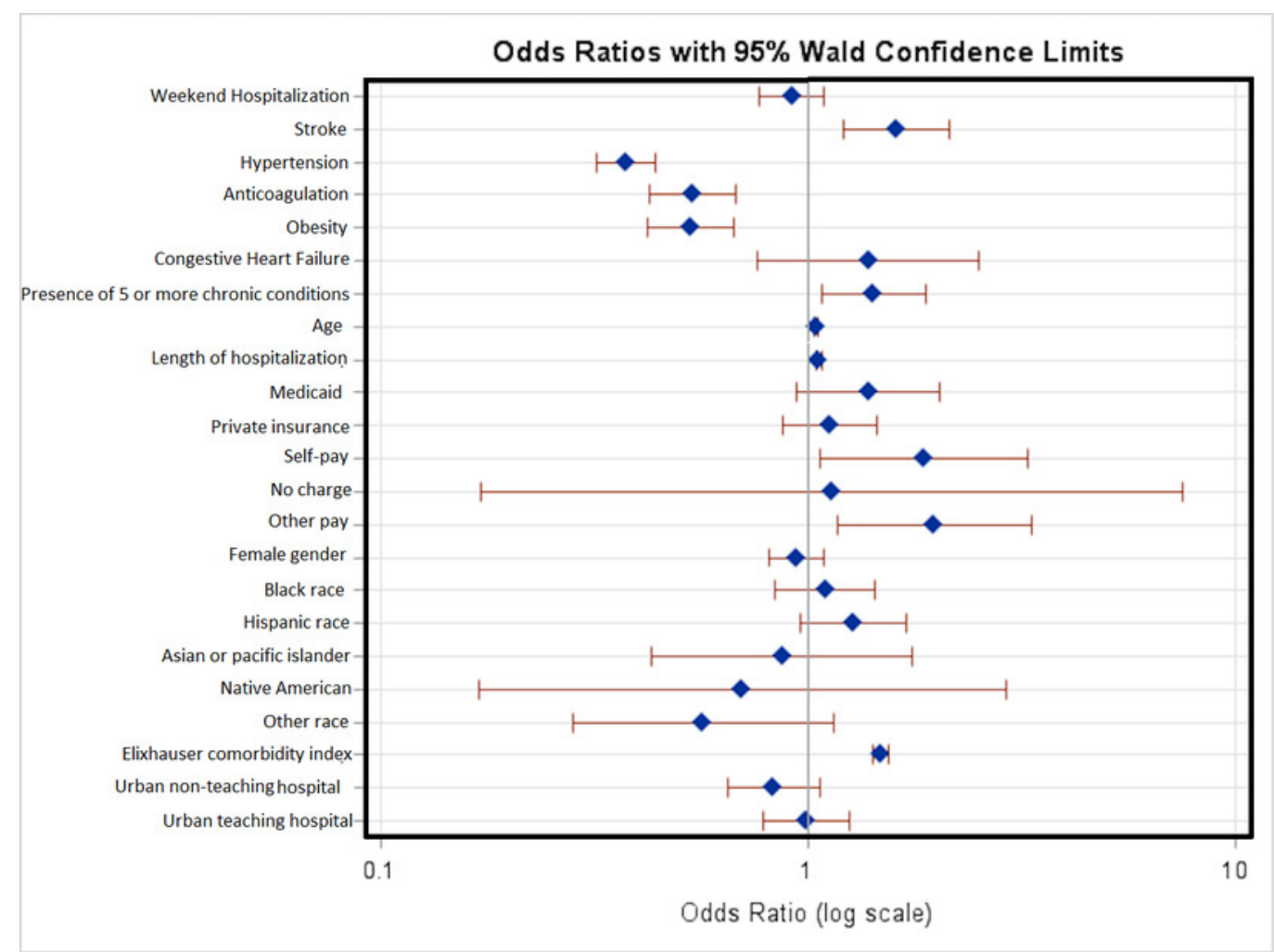




\section{Table $\mathbf{1}$ (on next page)}

Baseline characteristics of atrial fibrillation (AF) hospitalizations

Table 1: The baseline characteristics indicate the percentage of AF hospitalizations admitted on the weekends and the weekdays. The total hospitalizations include both groups. The $\mathrm{P}$ value indicates the chi-square test for the baseline characteristic differences among the weekday and the weekend groups. 
1 Table 1 Baseline characteristics of atrial fibrillation (AF) hospitalizations

2

\begin{tabular}{|c|c|c|c|c|}
\hline Characteristic & $\frac{\frac{\text { Weekday }}{\text { hospitalization }}}{(\mathrm{n}=361,285)}$ & $\frac{\frac{\text { Weekend }}{\text { hospitalizations }}}{(\mathrm{n}=92,220)}$ & $\frac{\frac{\text { Total }}{\text { hospitalizations }}}{(\mathrm{n}=453,505)}$ & P Value \\
\hline $\begin{array}{l}\text { Mean age (years) } \pm \\
\text { (Standard deviation) }\end{array}$ & $70.1 \pm 13.5$ & $70.2 \pm 14.2$ & $70.1 \pm 13.6$ & 0.5338 \\
\hline $\begin{array}{l}\text { Gender } \\
\text { Male } \\
\text { Female } \\
\end{array}$ & $\begin{array}{l}50.53 \% \\
49.46 \% \\
\end{array}$ & $\begin{array}{l}48.13 \% \\
51.86 \% \\
\end{array}$ & $\begin{array}{l}50.0 \% \\
49.95 \% \\
\end{array}$ & $<0.0001$ \\
\hline $\begin{array}{l}\text { Race } \\
\text { White } \\
\text { Black } \\
\text { Hispanic } \\
\text { Asian } \\
\text { Native American } \\
\text { Other }\end{array}$ & $\begin{array}{l}82.6 \% \\
8.18 \% \\
5.34 \% \\
1.36 \% \\
0.38 \% \\
2.10 \%\end{array}$ & $\begin{array}{l}80.31 \% \\
9.03 \% \\
6.25 \% \\
1.66 \% \\
0.43 \% \\
2.30 \%\end{array}$ & $\begin{array}{l}82.1 \% \\
8.36 \% \\
5.53 \% \\
1.42 \% \\
0.39 \% \\
2.14 \%\end{array}$ & $<0.0001$ \\
\hline $\begin{array}{l}\text { Primary Payer } \\
\text { Medicare } \\
\text { Medicaid } \\
\text { Private } \\
\text { Self-pay } \\
\text { No charge } \\
\text { Other }\end{array}$ & $\begin{array}{l}66.95 \% \\
5.84 \% \\
22.61 \% \\
2.43 \% \\
0.27 \% \\
1.86 \%\end{array}$ & $\begin{array}{l}67.83 \% \\
6.41 \% \\
20.63 \% \\
2.94 \% \\
0.38 \% \\
1.78 \%\end{array}$ & $\begin{array}{l}67.13 \% \\
5.96 \% \\
22.21 \% \\
2.54 \% \\
0.29 \% \\
1.84 \%\end{array}$ & $<0.0001$ \\
\hline $\begin{array}{l}\text { Hospital region } \\
\text { Northeast } \\
\text { Midwest } \\
\text { South } \\
\text { West }\end{array}$ & $\begin{array}{l}21.10 \% \\
24.55 \% \\
39.71 \% \\
14.62 \%\end{array}$ & $\begin{array}{l}20.07 \% \\
23.65 \% \\
40.34 \% \\
15.92 \%\end{array}$ & $\begin{array}{l}20.89 \% \\
24.37 \% \\
39.84 \% \\
14.89 \%\end{array}$ & $<0.0001$ \\
\hline $\begin{array}{l}\text { Type of admission } \\
\text { Elective } \\
\text { Non-Elective }\end{array}$ & $\begin{array}{l}14.34 \% \\
85.65 \%\end{array}$ & $\begin{array}{l}4.14 \% \\
95.85 \%\end{array}$ & $\begin{array}{l}12.26 \% \\
87.73 \%\end{array}$ & $<0.0001$ \\
\hline $\begin{array}{l}\text { Hospital } \\
\text { location/teaching } \\
\text { status } \\
\text { Rural } \\
\text { Urban non- } \\
\text { teaching } \\
\text { Urban teaching }\end{array}$ & $\begin{array}{l}11.22 \% \\
28.65 \% \\
60.12 \%\end{array}$ & $\begin{array}{l}11.72 \% \\
30.63 \% \\
57.63 \%\end{array}$ & $\begin{array}{l}11.32 \% \\
29.05 \% \\
59.61 \%\end{array}$ & $<0.0001$ \\
\hline $\begin{array}{l}\text { Hospital bed size } \\
\text { Small }\end{array}$ & $18.88 \%$ & $19.60 \%$ & $19.03 \%$ & $<0.0001$ \\
\hline
\end{tabular}




\begin{tabular}{|l|l|l|l|l|}
\hline \multicolumn{1}{|c|}{$\begin{array}{l}\text { Medium } \\
\text { Large }\end{array}$} & $\begin{array}{l}30.02 \% \\
51.08 \%\end{array}$ & $\begin{array}{l}31.45 \% \\
48.93 \%\end{array}$ & $\begin{array}{l}30.31 \% \\
50.64 \%\end{array}$ & \\
\hline $\begin{array}{l}\mathrm{CHA}_{2} \mathrm{DS}_{2} \mathrm{VASc} \\
\text { score (mean } \pm \\
\text { standard deviation) }\end{array}$ & $2.73 \pm 1.44$ & $2.79 \pm 1.47$ & $2.74 \pm 1.45$ & $<0.0001$ \\
\hline
\end{tabular}

3

4

5

6

7

8 


\section{Table 2 (on next page)}

Differences between outcomes for the weekday and weekend hospitalizations for Atrial Fibrillation (AF)

Table 2: The differences in the the weekday and the weekend hospitalizations indicates the percentage of hospitalizations for AF. The P value indicates the differences in these groups after performing the chi-square and t-test. 
1 Table 2 Differences between weekday and weekend hospitalizations for Atrial Fibrillation

2

\begin{tabular}{|l|l|l|l|}
\hline Variable & $\begin{array}{l}\text { Weekend admission } \\
(\mathrm{n}=92,220)\end{array}$ & $\begin{array}{l}\text { Weekday admission } \\
(\mathrm{n}=361,285)\end{array}$ & $\mathrm{P}$-value \\
\hline Cardioversion & $2.90 \%$ & $14.83 \%$ & $\mathrm{P}<0.0001$. \\
\hline $\begin{array}{l}\text { Mean length of stay } \\
\text { (days) } \pm \text { Standard } \\
\text { deviation }\end{array}$ & $3.49 \pm 3.70$ & $3.47 \pm 3.50$ & $\mathrm{P}=0.4233$. \\
\hline In-hospital mortality & $0.19 \%$ & $0.74 \%$ & $\mathrm{P}=0.9058$. \\
\hline $\begin{array}{l}\text { Mean cost of } \\
\text { hospitalization } \\
\text { (USD) }\end{array}$ & 8265.8 & 8966.5 & $\mathrm{P}<0.001$. \\
\hline $\begin{array}{l}\text { Time to } \\
\text { cardioversion (days) } \\
\pm \text { (standard } \\
\text { deviation) }\end{array}$ & $1.94 \pm 2.40$ & $1.73 \pm 3.96$ & $\mathrm{P}=0.0005$ \\
\hline Anticoagulation & $17.09 \%$ & $18.73 \%$ & $<0.0001$ \\
\hline
\end{tabular}

3

4

5 


\section{Table 3(on next page)}

Unadjusted estimates for in-hospital mortality for AF hospitalizations.

Table 3: The unadjusted odds ratios indicate the univariate association between the comorbidity listed in the first column to the in-hospital mortality. This indicates the strength of association without adjusting for other variables. 


\begin{tabular}{|l|r|r|r|l|}
\hline \multicolumn{6}{|l|}{ Unadjusted odds ratio's to in-hospital mortality } \\
\hline & OR & $95 \%$ Confidence Interval & P-value \\
\hline Stroke & 2.67 & 2.07 & 3.45 & $<0.0001$ \\
\hline Hypertension & 0.73 & 0.63 & 0.85 & $<0.0001$ \\
\hline Anticoagulation & 0.52 & 0.42 & 0.66 & $<0.0001$ \\
\hline Obesity & 0.59 & 0.48 & 0.73 & $<0.0001$ \\
\hline Congestive Heart Failure & 8.27 & 5.14 & 13.32 & $<0.0001$ \\
\hline =>5 Chronic Conditions & 3.12 & 2.44 & 3.98 & $<0.0001$ \\
\hline Weekend admission & 1.01 & 0.85 & 1.19 & 0.0140 \\
\hline Female & 1.24 & 1.09 & 1.42 & 0.0011 \\
\hline
\end{tabular}

1

2

3 Table 3: Unadjusted estimates for in-hospital mortality for AF hospitalizations. 


\section{Table 4 (on next page)}

Multivariate logistic regression analysis showing the adjusted odds ratio's predicting the in-hospital mortality for Atrial Fibrillation (AF) hospitalizations.

Table 4: The adjusted odds ratio's, 95\% confidence intervals and their P-values represent the odds of in-hospital mortality after adjusting for the covariates listed in the table. 


\begin{tabular}{|c|c|c|c|c|}
\hline \multicolumn{5}{|l|}{ Odds Ratio Estimates } \\
\hline \multirow{2}{*}{$\begin{array}{l}\text { Effect } \\
\text { Weekend hospitalization }\end{array}$} & \multirow{2}{*}{\begin{tabular}{|l} 
Adjusted Odds Ratio \\
0.917 \\
\end{tabular}} & \multicolumn{2}{|c|}{$\begin{array}{l}\text { 95\% Confidence } \\
\text { Limits }\end{array}$} & \multirow{2}{*}{$\begin{array}{l}\text { P-value } \\
0.3299 \\
\end{array}$} \\
\hline & & 0.77 & 1.092 & \\
\hline Stroke & 1.609 & 1.214 & 2.132 & 0.0009 \\
\hline Hypertension & 0.376 & 0.32 & 0.441 & $<.0001$ \\
\hline Anticoagulation & 0.538 & 0.427 & 0.679 & $<.0001$ \\
\hline Obesity & 0.529 & 0.42 & 0.667 & $<.0001$ \\
\hline Congestive Heart Failure & 1.383 & 0.76 & 2.516 & 0.2886 \\
\hline$=>5$ Chronic Conditions & 1.423 & 1.074 & 1.886 & 0.014 \\
\hline AGE & 1.048 & 1.039 & 1.057 & $<.0001$ \\
\hline Length of stay & 1.059 & 1.043 & 1.076 & $<.0001$ \\
\hline \multicolumn{5}{|l|}{ EXPECTED PRIMARY PAYER } \\
\hline \multicolumn{5}{|l|}{ Medicare (Reference group) } \\
\hline Medicaid & 1.385 & 0.941 & 2.039 & 0.0984 \\
\hline Private insurance & 1.124 & 0.873 & 1.448 & 0.3643 \\
\hline Self-pay & 1.868 & 1.065 & 3.275 & 0.0292 \\
\hline No charge & 1.14 & 0.172 & 7.552 & 0.8918 \\
\hline Other pay & 1.978 & 1.175 & 3.329 & 0.0103 \\
\hline Female gender & 0.936 & 0.807 & 1.086 & 0.3814 \\
\hline \multicolumn{5}{|l|}{ RACE } \\
\hline \multicolumn{5}{|l|}{ White (Reference group) } \\
\hline Black & 1.099 & 0.837 & 1.441 & 0.4971 \\
\hline Hispanic & 1.273 & 0.956 & 1.695 & 0.0986 \\
\hline Asian or pacific islander & 0.869 & 0.43 & 1.757 & 0.6962 \\
\hline Native American & 0.702 & 0.169 & 2.911 & 0.6259 \\
\hline Other & 0.569 & 0.282 & 1.146 & 0.1144 \\
\hline Elixhauser comorbidity index & 1.474 & 1.412 & 1.538 & $<.0001$ \\
\hline \multicolumn{5}{|c|}{ HOSPITAL LOCATION AND TEACHING STATUS } \\
\hline \multicolumn{5}{|c|}{ Rural hospital (Reference group) } \\
\hline Urban non-teaching hospital & 0.832 & 0.651 & 1.064 & 0.143 \\
\hline Urban teaching hospital & 0.99 & 0.788 & 1.244 & 0.933 \\
\hline
\end{tabular}

3

4

5 Table 4: Multivariate logistic regression analysis showing the adjusted odds ratio's predicting

6 the in-hospital mortality for Atrial Fibrillation (AF) hospitalizations. 